\title{
Tối ưu hóa phản ứng realtime PCR nhằm phát hiện Streptococcus agalactiae
}

\section{Optimize realtime PCR reaction to detect Streptococcus agalactiae}

\author{
Nguyễn Thị Thanh Thảo ${ }^{1}$, Nguyễn Thị Trúc Phương ${ }^{2}$, Nguyễn Thị Trúc $\mathrm{Anh}^{3}$, \\ Lương Thị Mỹ Ngân ${ }^{4 *}$ \\ ${ }^{1}$ Trường Đại học Mở Thành phố Hồ Chí Minh, Việt Nam \\ ${ }^{2}$ Công ty cổ phần Công nghệ TBR, TP. Hồ Chí Minh, Việt Nam \\ ${ }^{3}$ Công ty cổ phần Trung tâm xét nghiệm chẩn đoán Y Khoa Hanhphuclab, Việt Nam \\ ${ }^{4}$ Trường Đại học Khoa học Tự nhiên - ĐHQG TP.HCM, Việt Nam \\ *Tác giả liên hệ, Email: ltmngan@hcmus.edu.vn
}

\begin{tabular}{|c|c|}
\hline THÔNG TIN & TÓM TẮT \\
\hline $\begin{array}{l}\text { DOI:10.46223/HCMCOUJS. } \\
\text { tech.vi.16.1.1867.2021 }\end{array}$ & $\begin{array}{l}\text { Streptococcus agalactiae (GBS) là tác nhân truyền nhiễm } \\
\text { hàng đầu gây nhiễm trùng huyết sơ sinh giai đoạn sớm. Tầm soát } \\
\text { GBS và tiêm kháng sinh dự phòng ở phụ nữ thai sản có thể giúp } \\
\text { ngăn chặn hữu hiệu tỷ lệ nhiễm GBS ở trẻ sơ sinh. Phương pháp } \\
\text { truyền thống phát hiện và nuôi cấy GBS trên đĩa thạch máu rất }\end{array}$ \\
\hline Ngày nhận & \\
\hline Ngày nhận lại: 04/05/2021 & $\begin{array}{l}\text { hành tôi ưu hóa phản ứng realtime } \mathrm{PCR} \text { với cặp mồi và mẫu dò } \\
\text { được thiết kế nhằm phát hiện gen đặc hiệu } c f b \text { của GBS. Các thí }\end{array}$ \\
\hline Duyệt đăng: 25/05/2021 & $\begin{array}{l}\text { nghiệm tối ưu hóa được thực hiện trên chủng S. agalactiae ATCC } \\
\text { 13813. Độ đặc hiệu của quy trình tối ưu được kiểm tra trên DNA } \\
\text { của chủng Staphylococcus aureus ATCC 25923, Gardnerella } \\
\text { vaginalis và Chlamydia trachomatis. Ngoài ra, quy trình tối ưu } \\
\text { được thử nghiệm trên } 30 \text { mẫu dịch phết âm đạo - trực tràng của } \\
\text { phụ nữ mang thai trong giai đoạn } 35-37 \text { tuần. Quy trình tối ưu đặc }\end{array}$ \\
\hline Tù khóa: & hiệu với chủng GBS, có độ nhạy 50 bản sao/phản ứng, độ chính \\
\hline $\begin{array}{l}\mathrm{cfb} ; \text { nhiễm trùng sơ sinh; } \\
\text { realtime PCR; Streptococcus } \\
\text { agalactiae }\end{array}$ & $\begin{array}{l}\text { xác } 99.94 \% \text {, và hiệu quả khuếch đại } \mathrm{E}_{\mathrm{A}} \%=94.5 \% \text {. Trong số } 30 \\
\text { mẫu thử nghiệm, } 10 \text { mẫu được phát hiện là có hiện diện của GBS, } \\
\text { trong khi nuôi cấy truyền thống chỉ phát hiện } 08 \text { mẫu có GBS. }\end{array}$ \\
\hline
\end{tabular}

ABSTRACT
Streptococcus agalactiae (GBS) is the major contagious
cause of early-onset sepsis in newborns. Screening and
intrapartum antibiotic prophylaxis for GBS in pregnant women
could effectively prevent early-onset GBS infection in newborns.
The conventional method for isolation and identification of GBS
on the blood plate medium is labor-intensive, time-consuming,
and low sensitive. This study is aimed to optimize parameters for
a realtime PCR reaction with primers and a probe designed to
detect GBS-specific cfb gene. The optimized experiments were
carried out on the strain S. agalactiae ATCC 13813. The
specificity of the optimized procedure was tested on DNA


Keywords:

cfb; neonatal sepsis; realtime PCR; Streptococcus agalactiae samples of Staphylococcus aureus ATCC 25923, Gardnerella vaginalis, and Chlamydia trachomatis. In addition, the optimized reaction was tested on 30 vaginal - rectal samples from pregnant women between 35-37 weeks gestation. The optimized procedure was specific to GBS with 50 copies/reaction sensitivity, an accuracy of $99.94 \%$, and amplification efficiency $\left(\mathrm{E}_{\mathrm{A}} \%\right)$ of 94.5\%. GBS was detected in ten samples among the 30 vaginalrectal samples by the realtime PCR, while only eight samples were found to be positive in the conventional plate method.

\section{Giới thiệu}

Nhiễm Trùng Huyết Sơ Sinh (NTHSS) là bệnh nhiễm khuẩn toàn thân, ảnh hưởng đến khoảng ba triệu trẻ em trên toàn thế giới với tỷ lệ tử vong 11-19\% (Molloy et al., 2020), là nguyên nhân phổ biến thứ ba gây tử vong ở trẻ sơ sinh (Kim, Polin, \& Hooven, 2020). NTHSS gây ra các biến chứng nguy hiểm như sinh non, các biến chứng liên quan đến phổi, nhiễm trùng huyết hoặc viêm màng não. Do đó, trẻ bị NTHSS dễ tử vong hoặc nếu sống sót cũng sẽ mang các di chứng và khuyết tật lớn suốt đời như suy giảm vận động, suy giảm phát triển thần kinh (Shah et al., 2008; Stoll et al., 2004). Tuy nhiên, các dấu hiệu lâm sàng để nhận biết NTHSS lại không đặc hiệu, thường bị bỏ sót, dẫn đến việc không được điều trị kịp thời (Carbone, Montecucco, \& Sahebkar, 2020).

Vi khuẩn Gram dương Streptococcus agalactiae, hay GBS (Group B Streptococcus), là tác nhân truyền nhiễm hàng đầu đối với NTHSS giai đoạn sớm (tuần đầu tiên sau khi sinh) (Kim et al., 2020; Schrag et al., 2016; Schuchat, 1998). Trẻ em bị nhiễm GBS giai đoạn sớm đều do lây từ mẹ trong lúc sinh (Schuchat, 1998). Có khoảng 15-30\% phụ nữ mang thai nhiễm GBS ở đường sinh dục hoặc đường tiêu hóa và một nửa số trẻ em do những phụ nữ này sinh ra sẽ nhiễm GBS (Rao \& Khanna, 2020). Điều trị dự phòng GBS trước sinh ở phụ nữ mang thai bằng kháng sinh làm giảm tới 80\% tỷ lệ mắc bệnh GBS (Fairlie, Zell, \& Schrag, 2013; Schrag \& Verani, 2013). Chính vì vậy, việc phát hiện GBS ở phụ nữ thai sản là rất cần thiết cho dự phòng trước sinh.

Phương pháp phát hiện GBS truyền thống thường tiến hành cấy mẫu trên đĩa thạch máu. Tuy nhiên phương pháp này có nhược điểm là thời gian phát hiện chậm và độ chính xác chưa cao. Vì vậy, các nghiên cứu hiện nay đang phát triển các phương pháp mới giúp nhận diện GBS trong mẫu nhanh và chính xác hơn. Các phương pháp phát hiện tác nhân gây NTHSS nói chung và GBS nói riêng dựa trên sinh học phân tử như PCR hay multiplex PCR đã được chứng minh có hiệu quả nhanh và nhạy hơn phương pháp cấy truyền thống (Lucignano et al., 2011; Shang, Chen, Wu, Du, \& Zhao, 2005).

Gen $c f b$, mã hóa cho nhân tố CAMP (CAMP factor) hiện diện trong hầu hết các loài GBS và được đánh giá là đặc trưng cho sự hiện diện của GBS. Nhiều nghiên cứu chọn làm đối tượng phân tử cho các phản ứng dựa trên PCR để kiểm tra sự có mặt của GBS (Ke et al., 2000; Lin et al., 2019; Mousavi, Hosseini, Mashouf, \& Arabestani, 2016; Podbielski, Blankenstein, \& Lütticken, 1994; Shabayek, Abdalla, \& Abouzeid, 2010; Vieira et al., 2019)

Nghiên cứu này được tiến hành nhằm xây dựng quy trình phát hiện GBS bằng kỹ thuật realtime PCR phát hiện gen đặc hiệu $c f b$ của GBS. 


\section{Vật liệu và phương pháp}

\subsection{Chủng vi khuẩn}

Streptococcus agalactiae ATCC 13813, Staphylococcus aureus ATCC 25923 được cung cấp bởi hãng MicroBiologics (Mỹ); Gardnerella vaginalis và Chlamydia trachomatis được cung cấp bởi công ty TBR.

\subsection{Các mẫu dịch phết âm đạo-trục tràng}

Các mẫu dịch phết âm đạo - trực tràng của 30 phụ nữ mang thai trong giai đoạn 35-37 tuần được đặt trong $05 \mathrm{~mL}$ môi trường vận chuyển Liquid Based Microbiology - LBM (Biomerieux, Pháp) được cung cấp bởi Trung tâm xét nghiệm chẩn đoán Y Khoa Hanhphuclab. Một phần thể tích các mẫu này $(01 \mathrm{~mL} / \mathrm{mẫu})$ được sử dụng trực tiếp cho tách chiết DNA và phần còn lại $(04 \mathrm{~mL})$ được vận chuyển đến Trung tâm Nam Khoa để tăng sinh và phân lập GBS.

\subsection{Môi truờng và điều kiện nuôi cấy vi khuẩn GBS}

Chủng chuẩn GBS ATCC 13813 ở dạng đông khô, được hoạt hóa bằng cách cấy trên đĩa thạch môi trường Blood Agar (BA, Merck, Đức) ở nhiệt độ $37^{\circ} \mathrm{C}, 24$ giờ. Sau đó tiến hành nuôi cấy vi khuẩn trong môi trường Brain Heart Infusion Broth $\left(\mathrm{BHIB}\right.$, Himedia) ở nhiệt độ $37^{\circ} \mathrm{C}$ trong thời gian 24 giờ.

\subsection{Thiết kế mồi và mẫu dò}

Trình tự mồi xuôi, mồi ngược và mẫu dò của gen $c f b$ của GBS được thiết kế dựa trên trình tự $c f b$ trên ngân hàng GenBank NCBI (n.d.), mã số truy cập MK134700.1, bằng chương trình OligoArchitectOnline của Sigma-Aldrich (n.d.) và chương trình Primer3 (n.d.). Các thông số của mồi và mẫu dò như chiều dài, nhiệt độ nóng chảy, phần trăm $\mathrm{GC}$, năng lượng cấu trúc thứ cấp sẽ được kiểm tra bằng công cụ OligoAnalyzer của IDT (n.d.). Độ đặc hiệu của mồi và mẫu dò được kiểm tra bằng công cụ BLAST của NCBI (n.d.).

\subsection{Tách chiết DNA}

Dịch nuôi cấy qua đêm $(03 \mathrm{~mL}, \mathrm{OD} 1.5)$ của S. agalactiae ATCC 13813 được ly tâm 13,000 vòng/phút, trong 05 phút nhằm thu nhận sinh khối. Tách chiết và tinh sạch DNA từ sinh khối vi khuẩn bằng bộ kit DNA Genome Extraction Kit ( $\mathrm{ABT}$, Việt Nam). Quy trình tách chiết thực hiện theo hướng dẫn của nhà sản xuất. DNA thu được có thể sử dụng ngay hoặc bảo quản ở $-20^{\circ} \mathrm{C}$. Nồng độ và chất lượng $\mathrm{DNA}$ sau khi tách chiết được kiểm tra bằng cách đo $\mathrm{OD}$ ở bước sóng $260 \mathrm{~nm}$ và $280 \mathrm{~nm}$.

Các mẫu dịch phết âm đạo - trực tràng của phụ nữ mang thai trong giai đoạn 35-37 tuần cũng được thu nhận DNA theo quy trình tương tự.

\subsection{Tối ưu phản úng realtime PCR}

2.6.1. Tối uu nhiệt độ bắt cặp, nồng độ mồi và mẫu dò

Các thông số nhằm tối ưu phản ứng realtime $\mathrm{PCR}$ được khảo sát trong nghiên cứu này là nhiệt độ bắt cặp, nồng độ mồi và mẫu dò cho khuếch đại đặc hiệu đoạn $c f b$ của GBS.

Phản ứng realtime PCR có các thành phần như Bảng 1.

\section{Bảng 1}

Thành phần và nồng độ các chất trong phản ứng realtime PCR 


\begin{tabular}{|l|c|}
\hline \multicolumn{1}{|c|}{ Thành phần } & Thể tích $(\boldsymbol{\mu L})$ \\
\hline Sensi Mix 2X & 10 \\
\hline Mồi xuôi GBS & 0.8 \\
\hline Mồi ngược GBS & 0.8 \\
\hline Mẫu dò GBS & 0.4 \\
\hline DNA vi khuẩn $(10 \mathrm{ng} / \mu \mathrm{L})$ & 5 \\
\hline Mồi xuôi IC* & 0.4 \\
\hline Mồi ngược IC* & 0.4 \\
\hline Mẫu dò IC* & 0.1 \\
\hline Plasmid mang IC* & 0.1 \\
\hline ddH ${ }_{2} \mathrm{O}$ & 2 \\
\hline Tổng & 20 \\
\hline
\end{tabular}

*Chứng nội (IC) là đoạn oligonucleotide có kích cỡ 198 cặp base, có trình tự không tương đồng với DNA của các vi khuẩn thử nghiệm, được chèn vào plasmid (Deer, Lampel, \& González-Escalona, 2010), có nồng độ $10^{9}$ bản $\mathrm{sao} / \mu \mathrm{L}$, được pha loãng để đạt nồng độ $10^{5}$ bản sao/phản ứng, đạt giá trị $\mathrm{Ct}$ từ $25-28$. Trình tự cặp mồi và mẫu dò cho IC (theo chiều 5'-3') như sau: Mồi xuôi IC: CTAACCTTCGTGATGAGCAATCG; Mồi ngược IC: GATCAGCTACGTGAGGTCCTAC; Mẫu dò IC: Hex-AGCTAGTCGATGCACTCCAGTCCTCCT- BHQ2 (Deer et al., 2010).

Nguồn: Kết quả xử lý dữ liệu từ điều tra của nhóm tác giả

Phản ứng realtime PCR được thực hiện với chu trình nhiệt như sau: 01 chu kỳ với nhiệt độ $95^{\circ} \mathrm{C}$ trong 10 phút, 45 chu kỳ với nhiệt độ $95^{\circ} \mathrm{C}$ trong 15 giây và nhiệt độ bắt cặp và kéo dài trong 60 giây.

Nhiệt độ bắt cặp theo gradient từ $55-65^{\circ} \mathrm{C}\left(55-55.7-57-59-61.4-63.3-64 \cdot 5-65^{\circ} \mathrm{C}\right)$. Mỗi nghiệm thức được lặp lại ba lần.

Nhiệt độ tối ưu được chọn để khảo sát tiếp cho các phản ứng khảo sát nồng độ mồi và mẫu dò. Các nồng độ mồi và mẫu dò được kết hợp với nhau thành các nghiệm thức theo Bảng 2 , và mỗi nghiệm thức được lặp lại ba lần. Mẫu chứng âm chứa $05 \mu \mathrm{L} \mathrm{ddH}_{2} \mathrm{O}$ thay cho mẫu DNA vi khuẩn.

\section{Bảng 2}

Các nghiệm thức khảo sát nồng độ mồi/mẫu dò

\begin{tabular}{|c|c|c|c|}
\hline Mẫu dò & Mồi & 400nM & 600nM \\
\hline $\mathbf{5 0 n M}$ & $200-50$ & $400-50$ & $600-50$ \\
\hline $\mathbf{1 0 0 n M}$ & $200-100$ & $400-100$ & $600-100$ \\
\hline $\mathbf{1 5 0 n M}$ & $200-150$ & $400-150$ & $600-150$ \\
\hline
\end{tabular}

Nguồn: Kết quả xử lý dữ liệu từ điều tra của nhóm tác giả 
Tín hiệu huỳnh quang được ghi nhận và được so sánh. Nhiệt độ bắt cặp, nồng độ mồi/mẫu dò tối ưu là nhiệt độ và nồng độ mà tại đó tín hiệu huỳnh quang đạt cao nhất và sớm nhất.

\subsubsection{Kiểm tra độ đặc hiệu của quy trình}

Các mẫu DNA của các chủng vi khuẩn Staphylococcus aureus ATCC 25923, Gardnerella vaginalis và Chlamydia trachomatis (TBR, Việt Nam) được sử dụng trong thí nghiệm kiểm tra độ đặc hiệu của bộ mồi/mẫu dò khuếch đại $c f b$ cho GBS. Nhiệt độ bắt cặp và nồng độ mồi/mẫu dò sử dụng theo kết quả của thí nghiệm tối ưu của mục 2.6.1. Bộ mồi/mẫu dò được đánh giá là đặc hiệu khi chỉ có phản ứng chứa DNA của GBS cho tín hiệu huỳnh quang.

\subsubsection{Khảo sát độ nhạy của quy trình}

Plasmid GBS chuẩn mang đoạn $92 \mathrm{bp}$ của gen $c f b$ với nồng độ $10^{9}$ bản sao/ $\mu \mathrm{L}$ được sử dụng làm chứng dương cho thí nghiệm khảo sát độ nhạy của bộ mồi và mẫu dò. Nồng độ GBS chuẩn được pha loãng theo bậc 10 theo thứ tự: $10^{5}, 10^{4}, 10^{3}, 10^{2}, 10,1$ bản sao/ $\mu \mathrm{L}$. Vậy số bản sao của $c f b$ trong mỗi phản ứng tương ứng là: $5 \times 10^{5}-5$ bản sao/phản ứng. Nhiệt độ bắt cặp và nồng độ mồi/mẫu dò sử dụng theo kết quả của thí nghiệm mục 2.6.1. Độ nhạy của quy trình (ngưỡng phát hiện) là nồng độ DNA (số bản sao/phản ứng) thấp nhất trong dãy nồng độ pha loãng mà tại đó tín hiệu huỳnh quang lớn hơn tín hiệu huỳnh quang nền. Mỗi nghiệm thức được lặp lại 03 lần. Độ chính xác và hiệu quả khuếch đại $(\mathrm{E} \%)$ được đánh giá lần lượt dựa trên hệ số tương quan $\mathrm{R}^{2}$ và $\mathrm{E}_{\mathrm{A}} \%=\left(10^{-1 / \text { slope }}-1\right)$ x $100 \%$. Sau đó, phản ứng realtime $\mathrm{PCR}$ được thực hiện 20 lần lặp lại tại giá trị chu kỳ ngưỡng phát hiện để khẳng định kết quả.

\subsection{Thử nghiệm quy trình tối ưu trên các mẫu dịch phết âm đạo - trục tràng}

Quy trình realtime PCR tối ưu được thử nghiệm với 30 mẫu DNA từ mẫu dịch phết âm đạo - trực tràng của phụ nữ mang thai. Đồng thời, các mẫu dịch phết âm đạo này được gửi đến Trung tâm Nam Khoa để kiểm tra sự hiện diện của GBS bằng phương pháp nuôi cấy truyền thống. Kết quả dương tính và âm tính với GBS được ghi nhận và so sánh hiệu quả giữa hai phương pháp.

\section{Kết quả và thảo luận}

\subsection{Thiết kế mồi và mẫu dò}

Cặp mồi và mẫu dò được thiết kế nhằm khuếch đại cho gen $c f b$ của GBS có trình tự được thể hiện ở Bảng 3. Các đặc tính vật lý của mồi và mẫu dò được phân tích bằng phần mềm OligoAnalyzer và được thể hiện ở Bảng 4 . Bảng 4 cho thấy rằng, các thông số như chiều dài, $\% \mathrm{GC}$, nhiệt độ nóng chảy, độ chênh lệch nhiệt độ nóng chảy và $\Delta \mathrm{G}(>-09 \mathrm{kcal} / \mathrm{mol})$ đều thỏa mãn yêu cầu trong thiết kế mồi. Tính đặc hiệu được kiểm tra bằng công cụ BLAST (NCBI) và kết quả cho thấy rằng khả năng bắt cặp đặc hiệu của mồi và mẫu dò trên vùng gen $c f b$ của các chủng vi khuẩn GBS, với mức độ tương đồng đạt $100 \%$, và không bắt lên các trình tự của sinh vật khác (dữ liệu không trình bày).

\section{Bảng 3}

Trình tự mồi và mẫu dò được thiết kế

\begin{tabular}{|l|l|}
\hline \multicolumn{1}{|c|}{ Tên } & \multicolumn{1}{c|}{ Trình tự (5' $\mathbf{- 3}$ ') } \\
\hline Mồi xuôi & TGAGGCTATTACTAGTGTTGAAA \\
\hline Mồi ngược & CTACACGACTACCAATAGAATTCA \\
\hline Mẫu dò & FAM-ATTGCGTGCCAACCCTGAGACAGT-BHQ1 \\
\hline
\end{tabular}

Nguồn: Kết quả xử lý dữ liệu từ điều tra của nhóm tác giả 


\section{Bảng 4}

Các đặc tính vật lý của mồi và mẫu dò

\begin{tabular}{|l|c|c|c|}
\multicolumn{1}{|c|}{ Thông số } & Mồi xuôi & Mồi ngược & Mẫu dò \\
\hline Chiều dài & 23 & 24 & 24 \\
\hline Phần trăm GC $(\%)$ & 34.8 & 37.5 & 54.2 \\
\hline Nhiệt độ nóng chảy $\left({ }^{\circ} \mathrm{C}\right)$ & 51.3 & 52.0 & 63.1 \\
\hline Cấu trúc hairpin $(\Delta \mathrm{G}, \mathrm{kcal} / \mathrm{mol})$ & 0.19 & -0.81 & -0.21 \\
\hline Cấu trúc self-dimer $(\Delta \mathrm{G}, \mathrm{kcal} / \mathrm{mol})$ & -6.84 & -8.51 & -6.21 \\
\hline Kích thước đoạn khuếch đại $(\mathrm{bp})$ & \multicolumn{2}{|c|}{$92 \mathrm{bp}$} & \\
\hline
\end{tabular}

Nguồn: Kết quả xử lý dữ liệu từ điều tra của nhóm tác giả

\subsection{Tối ưu hóa phản úng realtime PCR}

DNA của chủng chuẩn vi khuẩn GBS ATCC 13813 sau nuôi cấy và tách chiết có nồng độ 35.219ng/ $\mu \mathrm{L}$, có tỉ lệ $\mathrm{A} 260 / 280=1.98$. Kết quả cho thấy rằng $\mathrm{DNA}$ sau tách chiết có độ tinh sạch cao, không bị lẫn protein. Có thể sử dụng mẫu DNA cho các thí nghiệm tối ưu hóa quy trình realtime PCR.

Nhiệt độ bắt cặp mồi, mẫu dò và DNA đích là một trong những yếu tố quan trọng trong hiệu quả khuếch đại. Kết quả khảo sát nhiệt độ bắt cặp mồi và mẫu dò nhằm khuếch đại gen $c f b$ được thể hiện ở Hình 1 . Kết quả cho thấy rằng ở tất cả nhiệt độ thuộc dãy nhiệt độ khảo sát đều có tín hiệu khuếch đại. Tuy nhiên, ở nhiệt độ $59^{\circ} \mathrm{C}$, tín hiệu khuếch đại cao nhất so với các nhiệt độ còn lại. Do đó, nhiệt độ bắt cặp thích hợp cho bộ mồi/mẫu dò được chọn trong các thí nghiệm kế tiếp là $59^{\circ} \mathrm{C}$.

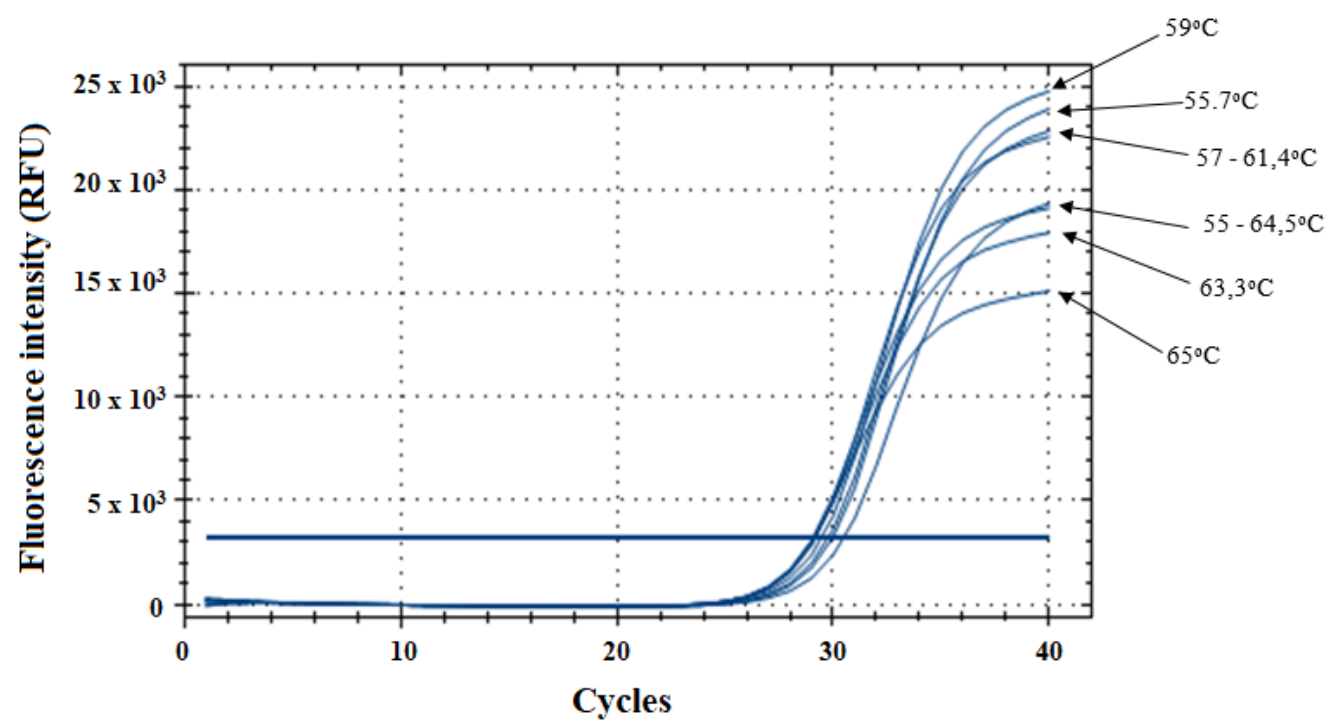

Hình 1. Kết quả gradient nhiệt độ bắt cặp

Nồng độ của mồi xuôi, mồi ngược và mẫu dò có ảnh hưởng rất lớn đến hiệu suất của phản ứng realtime PCR. Trong số các nghiệm thức khảo sát (Bảng 2) thì ở nồng độ mồi 400nM và nồng độ mẫu dò $150 \mathrm{nM}$, phản ứng realtime $\mathrm{PCR}$ cho tín hiệu khuếch đại cao nhất, đồng thời 
cho giá trị Ct sớm nhất (20.59) so với các nồng độ khác (Hình 2). Vì thế, nồng độ mồi và mẫu dò được chọn cho các thí nghiệm tiếp theo lần lượt là $400 \mathrm{nM}$ và $150 \mathrm{nM}$.

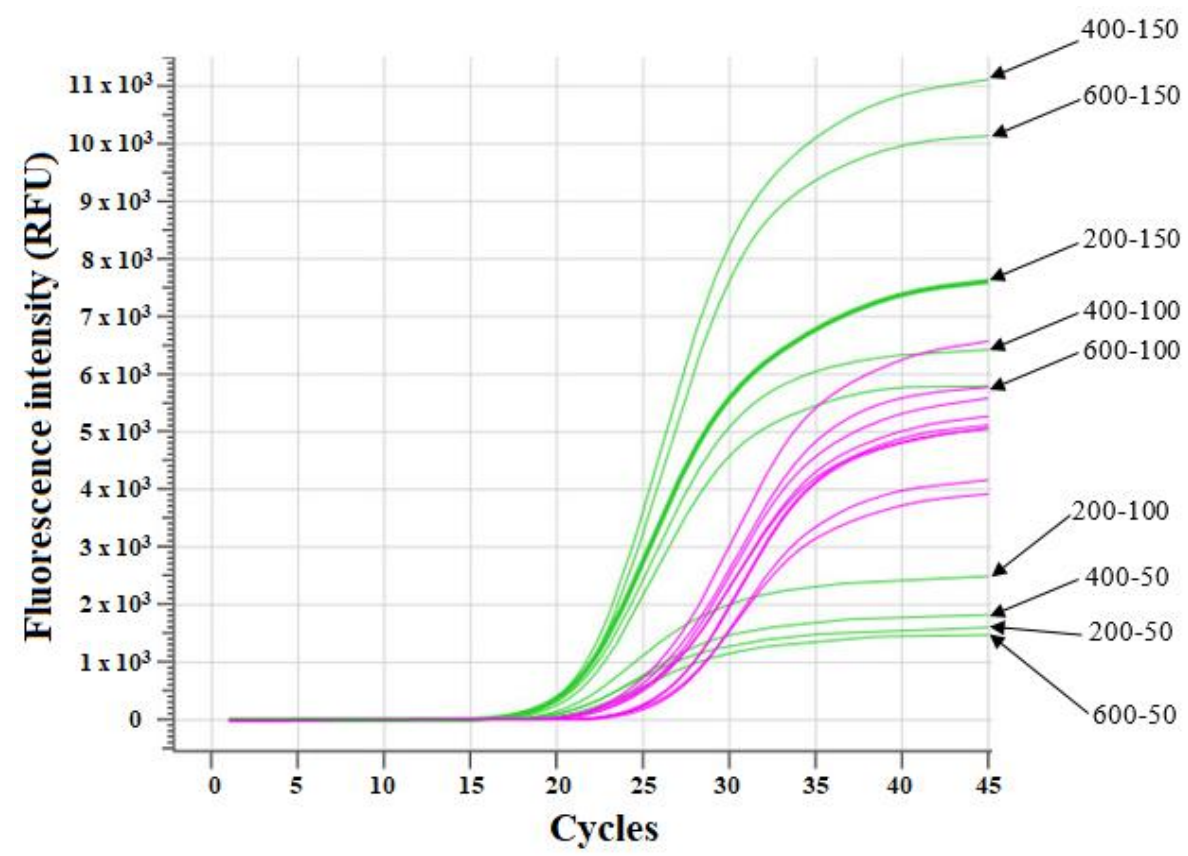

Hình 2. Kết quả khảo sát nồng độ mồi/mẫu dò

\section{3. Độ đặc hiệu của mồi/mấu dò}

Để có kết quả nhận diện GBS chính xác thì bộ mồi/mẫu dò phải bắt đặc hiệu trên DNA của GBS, và không bắt lên trình tự DNA của các vi khuẩn khác. Thí nghiệm sử dụng các mẫu DNA của 03 loại vi khuẩn thường gặp trong mẫu dịch phết âm đạo là $G$. vaginalis, $C$. trachomatis và $S$. aureus để kiểm tra độ đặc hiệu. Kết quả Hình 3 cho thấy mẫu âm và các mẫu vi khuẩn $G$. vaginalis, $C$. trachomatis và $S$. aureus không cho tín hiệu huỳnh quang, IC cho giá trị $\mathrm{Ct}$ 26.5, và chứng dương GBS cho tín hiệu dương tính. Như vậy, bộ mồi/mẫu dò sử dụng trong nghiên cứu này có tính đặc hiệu cao đối với GBS.

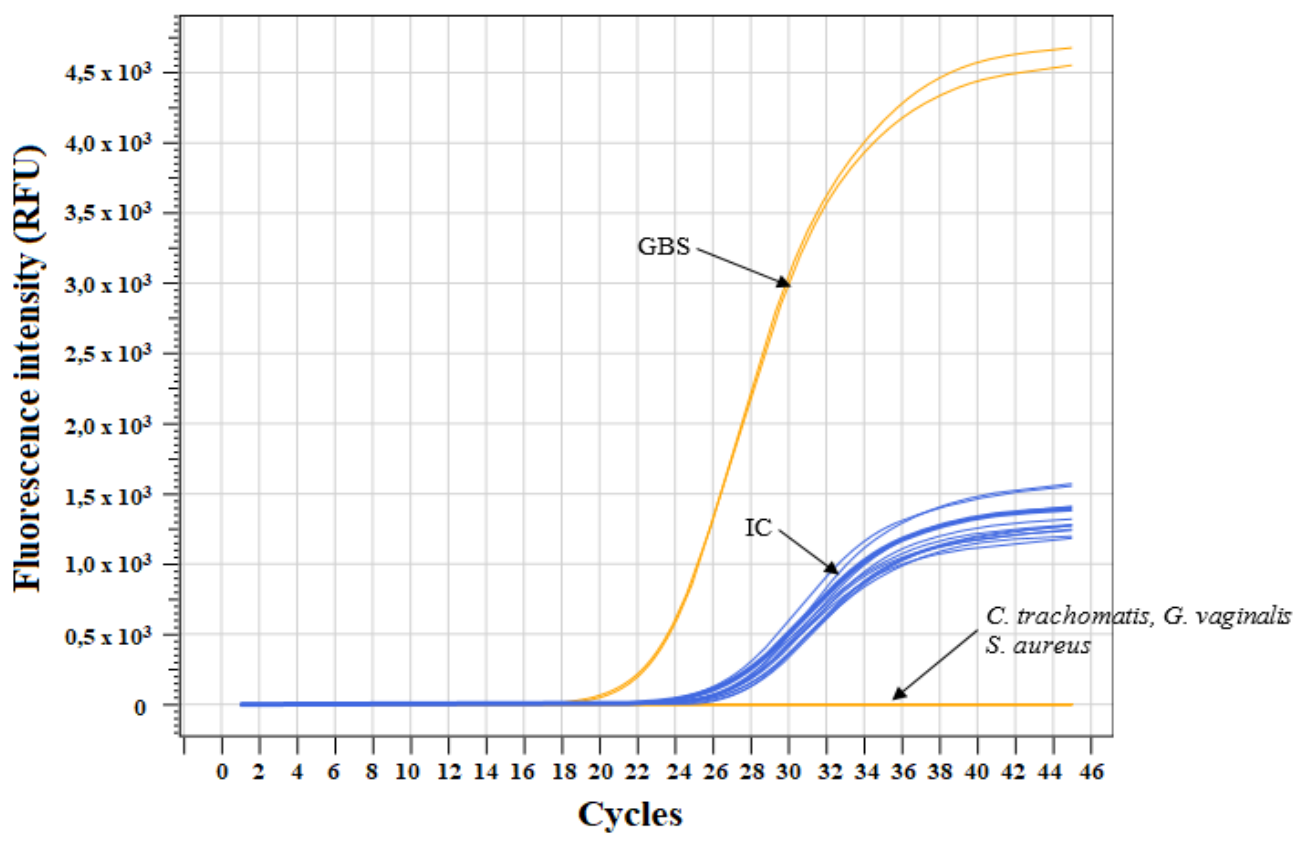

Hình 3. Kết quả độ đặc hiệu 


\section{4. Độ nhạy của bộ mồi/mẫu dò}

Kết quả kiểm tra độ nhạy của bộ mồi/mẫu dò nhằm khuếch đại đoạn đặc hiệu của gen $c f b$ có trong mẫu plasmid GBS chuẩn cho thấy rằng: ở các phản ứng có số bản sao từ $5 \times 10^{5}-50$ bản sao đều cho tín hiệu huỳnh quang và tín hiệu huỳnh quang thấp nhất tương ứng với 50 bản sao với giá trị chu kỳ ngưỡng $\mathrm{Ct}$ là: 37.86 chu kỳ (Hình 4). Đồ thị thể hiện mối quan hệ tuyến tính giữa số bản sao có trong mẫu chuẩn và chu kỳ ngưỡng được biểu thị ở Hình 5 , với giá trị $\mathrm{R}^{2}$ $=0.9994$. Kết quả phản ứng realtime PCR với mẫu plasmid GBS chuẩn ở nồng độ 50 bản sao/phản ứng được ghi nhận ở Hình 6 . Kết quả cho thấy rằng tín hiệu huỳnh quang được ghi nhận rất rõ ràng và có giá trị $\mathrm{Ct}: 36.77 \pm 0.71$. Vậy số bản sao $c f b$ thấp nhất mà bộ mồi/mẫu dò có thể phát hiện được là 50 bản sao/phản ứngvới độ chính xác $99.94 \%$ và hiệu quả khuếch đại $\mathrm{E}_{\mathrm{A}} \%=94.5 \%$.

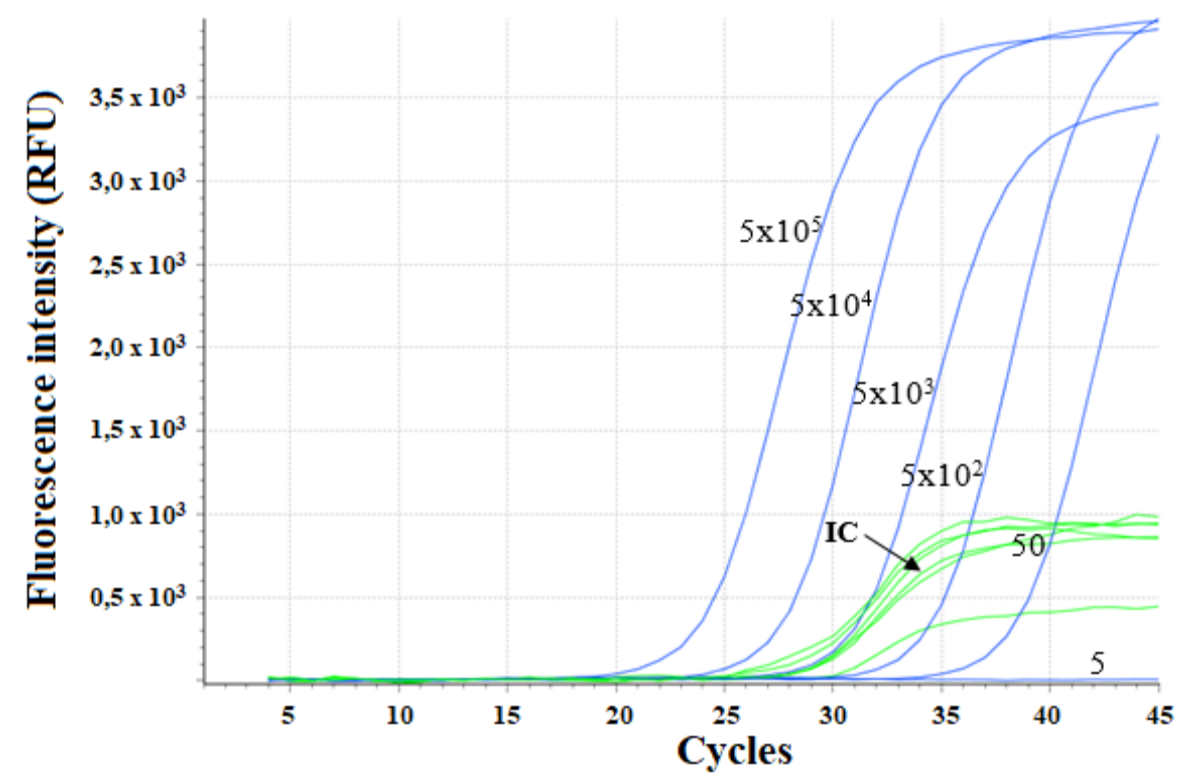

Hình 4. Kết quả kiểm tra độ nhạy

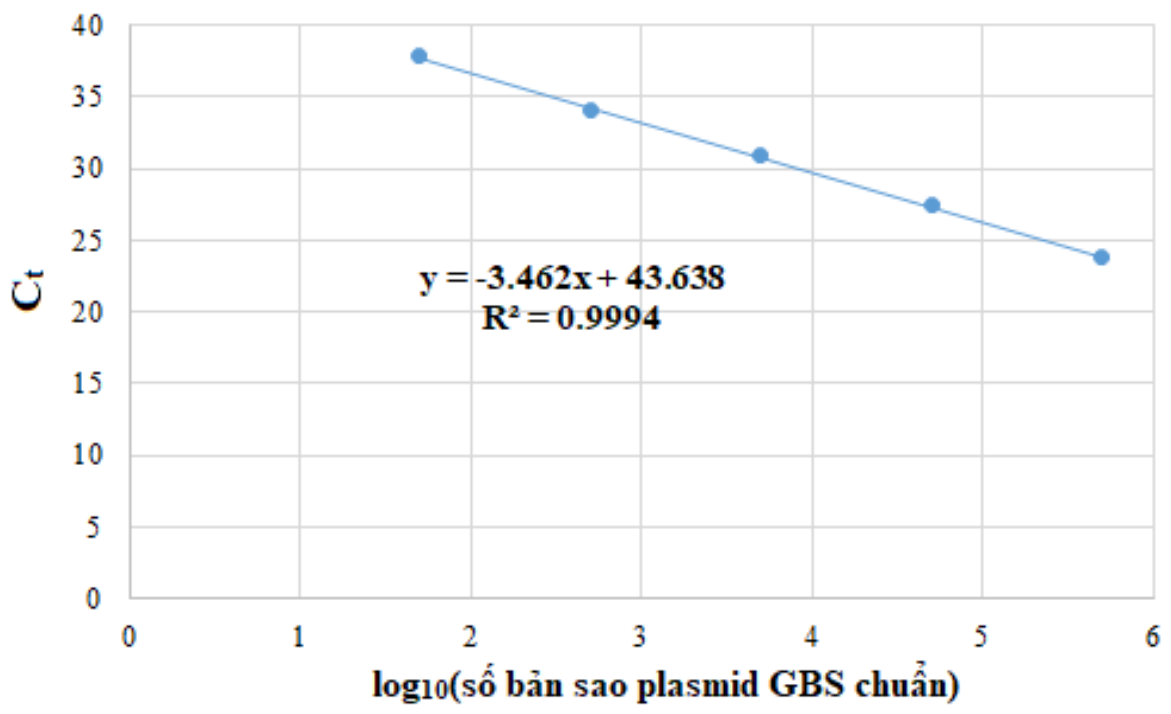

Hình 5. Đường chuẩn độ nhạy của bộ mồi/mẫu dò 


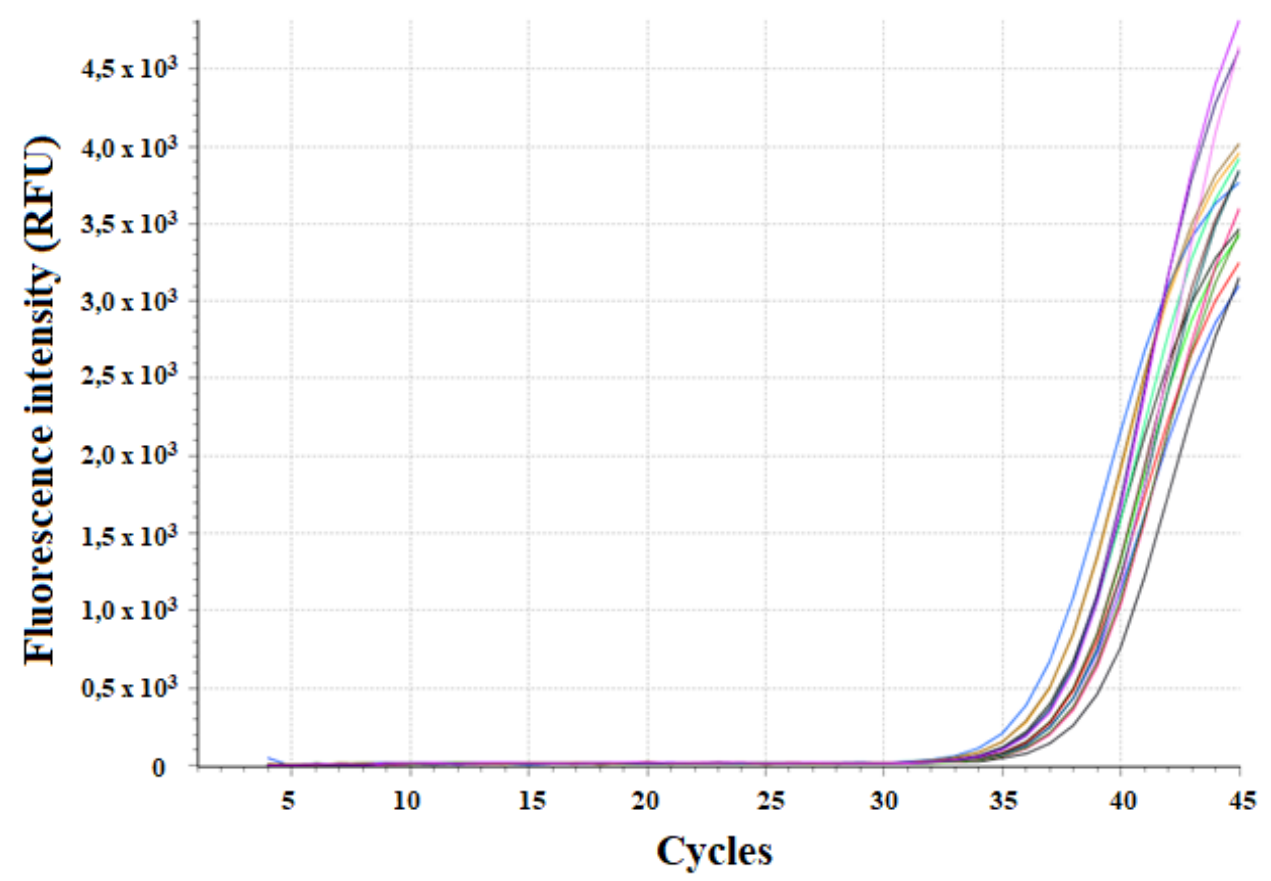

Hình 6. Khuếch đại đoạn đặc hiệu $c f b$ với plasmid GBS chuẩn ở nồng độ 50 bản sao/phản ứng

\subsection{Thử nghiệm quy trình tối uu trên các mẫu dịch phết âm đạo - trục tràng}

30 mẫu DNA tách từ dịch phết âm đạo - trực tràng. Kết quả cho thấy, có 10 mẫu trong tổng số 30 mẫu dịch phết âm đạo - trực tràng dương tính với GBS (Hình 7). Trong 10 mẫu dương tính, có 08 mẫu tín hiệu lên rất rõ (mẫu $06,10,12,15,20,25,28$ và mẫu 29) và 02 mẫu dương tính yếu (mẫu 01 và mẫu 11 ). Đáng lưu ý là các mẫu có hàm lượng $\mathrm{DNA}$ và tỉ lệ $\mathrm{A}_{260} / \mathrm{A}_{280}$ thấp như mẫu 06,20 và mẫu 28 (Bảng 5), nhưng tín hiệu huỳnh quang rất rõ. Điều này chứng tỏ rằng qui trình này có thể phát hiện đặc hiệu GBS trong mẫu với độ tinh sạch không cao. Trong khi đó, với phương pháp nuôi cấy truyền thống thì trong số 30 mẫu có 08 mẫu dương tính với GBS. Đây cũng là 08 mẫu cho tín hiệu mạnh trong phản ứng realtime PCR. Tỷ lệ nhiễm GBS trong 30 mẫu dịch phết kiểm tra bằng realtime $\mathrm{PCR}$ là $33.3 \%$ và bằng phương pháp nuôi cấy truyền thống là $26.7 \%$. Như vậy, tỷ lệ nhận diện bằng realtime PCR nhạy hơn so với nuôi cấy truyền thống.

\section{Bảng 5}

Kết quả đo OD mẫu DNA từ GBS ATCC 13813 và mẫu dịch phết âm đạo - trực tràng

\begin{tabular}{|l|c|c|l|c|c|}
\hline \multicolumn{1}{|c|}{ Mẫu } & $\begin{array}{c}\text { Nồng độ } \\
(\mathbf{n g} / \boldsymbol{\mu L})\end{array}$ & $\mathbf{A 2 6 0 / 2 8 0}$ & \multicolumn{1}{|c|}{ Mẫu } & $\begin{array}{c}\text { Nồng độ } \\
(\mathbf{n g} / \boldsymbol{\mu L})\end{array}$ & $\mathbf{A 2 6 0 / 2 8 0}$ \\
\hline $\begin{array}{l}\text { Chủng chuẩn } \\
\text { ATCC }\end{array}$ & 35.219 & 1.957 & Mẫu 16 & 2.976 & 1.186 \\
\hline Mẫu 1 & 19.123 & 1.757 & Mẫu 17 & 3.062 & 1.512 \\
\hline Mẫu 2 & 18.500 & 1.927 & Mẫu 18 & 6.580 & 1.757 \\
\hline Mẫu 3 & 3.047 & 1.224 & Mẫu 19 & 1.050 & 1.687 \\
\hline Mẫu 4 & 4.895 & 3.472 & Mẫu 20 & 1.507 & 0.404 \\
\hline
\end{tabular}




\begin{tabular}{|l|c|c|l|c|c|}
\hline \multicolumn{1}{|c|}{ Mẫu } & \multicolumn{1}{|c|}{$\begin{array}{c}\text { Nồng độ } \\
(\mathbf{n g} / \boldsymbol{\mu L})\end{array}$} & $\mathbf{A 2 6 0 / 2 8 0}$ & \multicolumn{1}{|c|}{ Mẫu } & $\begin{array}{c}\text { Nồng độ } \\
(\mathbf{n g} / \boldsymbol{\mu L})\end{array}$ & A260/280 \\
\hline Mẫu 5 & 3.130 & 1.815 & Mẫu 21 & 1.227 & 0.579 \\
\hline Mẫu 6 & 2.876 & 0.878 & Mẫu 22 & 7.775 & 1.323 \\
\hline Mẫu 7 & 3.047 & 1.224 & Mẫu 23 & 2.416 & 1.115 \\
\hline Mẫu 8 & 5.025 & 1.244 & Mẫu 24 & 1.407 & 1.863 \\
\hline Mẫu 9 & 4.247 & 1.154 & Mẫu 25 & 6.194 & 1.716 \\
\hline Mẫu 10 & 6.183 & 1.949 & Mẫu 26 & 3.432 & 2.078 \\
\hline Mẫu 11 & 4.534 & 1.414 & Mẫu 27 & 3.398 & 2.763 \\
\hline Mẫu 12 & 3.052 & 1.745 & Mẫu 28 & 2.735 & 0.995 \\
\hline Mẫu 13 & 2.957 & 1.987 & Mẫu 29 & 3.047 & 1.745 \\
\hline Mẫu 14 & 2.391 & 1.312 & Mẫu 30 & 3.058 & 1.687 \\
\hline Mẫu 15 & 3.666 & 1.502 & & & \\
\hline
\end{tabular}

Nguồn: Kết quả xử lý dữ liệu từ điều tra của nhóm tác giả

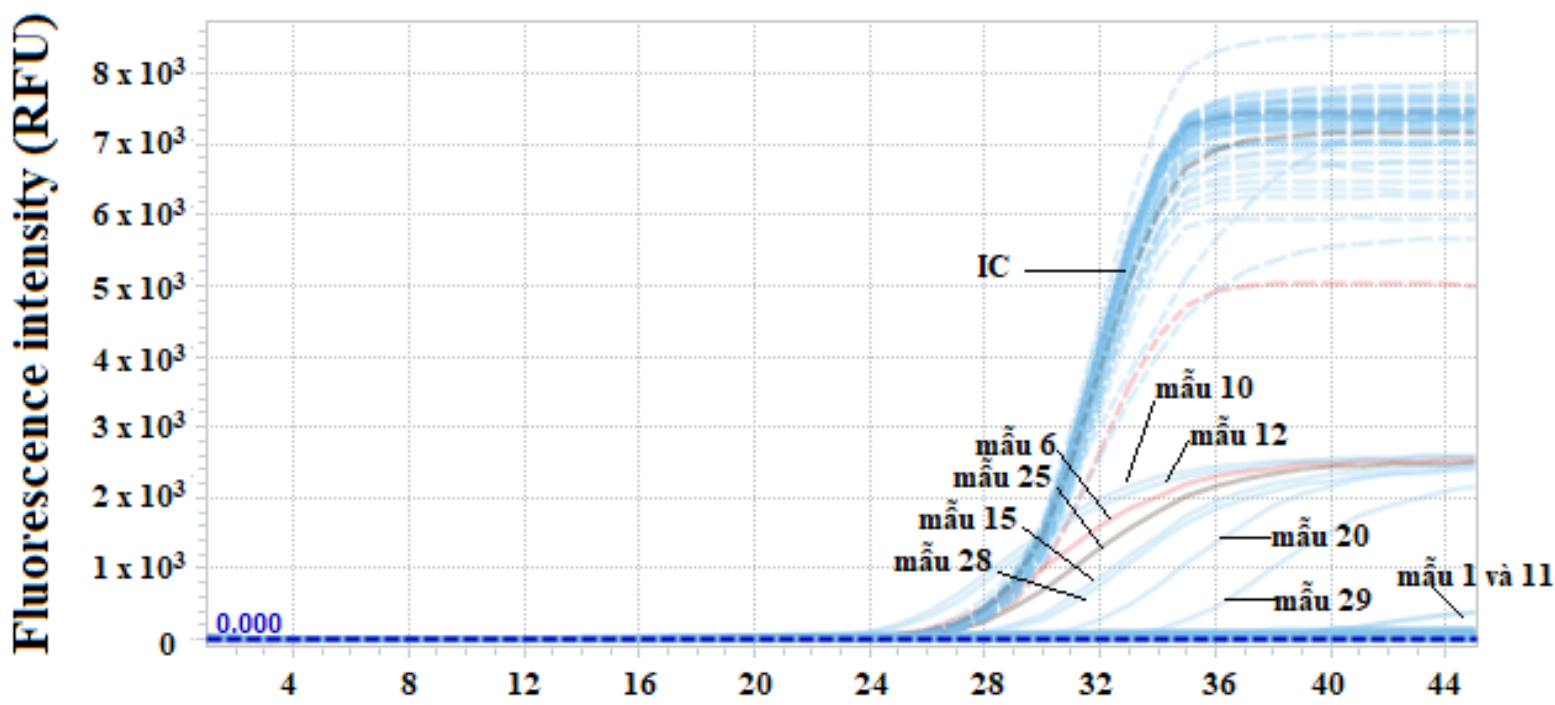

Cycles

Hình 7. Kết quả realtime PCR nhận diện GBS trên 30 mẫu dịch phết âm đạo - trực tràng

Một số nghiên cứu trên thế giới (Bảng 6) cũng cho thấy rằng phương pháp realtime $\mathrm{PCR}$ có khả năng nhận diện GBS cao hơn so với phương pháp nuôi cấy truyền thống tuy là tỉ lệ nhiễm ở các nghiên cứu có khác nhau. Điều này có thể do sự khác nhau về cỡ mẫu thí nghiệm và khu vực nghiên cứu. 


\section{Bảng 6}

Tỷ lệ nhận diện GBS bằng phương pháp realtime $\mathrm{PCR}$ gen $c f b$ và phương pháp nuôi cấy truyền thống của một số nghiên cứu trên thế giới

\begin{tabular}{|c|c|c|l|}
\hline STT & $\begin{array}{c}\text { Realtime PCR } \\
\text { gen } \boldsymbol{c f b}\end{array}$ & $\begin{array}{c}\text { Nuôi cấy } \\
\text { truyền thống }\end{array}$ & \multicolumn{1}{c|}{ Tài liệu tham khảo } \\
\hline 1 & $30.6 \%$ & $25.3 \%$ & (Shabayek et al., 2010) \\
\hline 2 & $26.6 \%$ & $24.4 \%$ & $\begin{array}{l}\text { (Carrillo-Ávila, Gutiérrez- } \\
\text { Fernández, González-Espín, } \\
\text { García-Triviño, \& Giménez- } \\
\text { Lirola, 2018) }\end{array}$ \\
\hline 3 & $51.1 \%$ & $14.3 \%$ & (Vieira et al., 2019) \\
\hline
\end{tabular}

Nguồn: Kết quả xử lý dữ liệu từ điều tra của nhóm tác giả

\section{Kết luận}

Nghiên cứu đã tối ưu hóa thành công phản ứng realtime PCR giúp phát hiện GBS nhanh chóng và hiệu quả. Kết quả thử nghiệm trên mẫu dịch phết âm đạo-trực tràng của phụ nữ mang thai bước đầu khẳng định sự khả thi của quy trình. Cần tiến hành nhiều mẫu thử nghiệm hơn nữa để quy trình có thể được đưa vào sử dụng trong các xét nghiệm thường quy.

\section{Tài liệu tham khảo}

Carbone, F., Montecucco, F., \& Sahebkar, A. (2020). Current and emerging treatments for neonatal sepsis. Expert Opinion on Pharmacotherapy, 21(5), 549-556.

Carrillo-Ávila, J., Gutiérrez-Fernández, J., González-Espín, A., García-Triviño, E., \& GiménezLirola, L. (2018). Comparison of qPCR and culture methods for group B Streptococcus colonization detection in pregnant women: Evaluation of a new qPCR assay. $B M C$ Infectious Diseases, 18(1), 1-8.

Deer, D., Lampel, K., \& González-Escalona, N. (2010). A versatile internal control for use as DNA in real-time PCR and as RNA in real-time reverse transcription PCR assays. Letters in Applied Microbiology, 50(4), 366-372.

Fairlie, T., Zell, E. R., \& Schrag, S. (2013). Effectiveness of intrapartum antibiotic prophylaxis for prevention of early-onset group B streptococcal disease. Obstetrics \& Gynecology, 121(3), 570-577.

IDT. (n.d.). Retrieved March 10, 2021, from https://www.idtdna.com/pages/tools/oligoanalyzer

Ke, D., Ménard, C., Picard, F. J., Boissinot, M., Ouellette, M., Roy, P. H., \& Bergeron, M. G. (2000). Development of conventional and real-time PCR assays for the rapid detection of group B streptococci. Clinical Chemistry, 46(3), 324-331.

Kim, F., Polin, R. A., \& Hooven, T. A. (2020). Neonatal sepsis. British Medical Journal, 371. doi:10.1136/bmj.m3672

Lin, Y., Ye, J., Luo, M., Hu, B., Wu, D., Wen, J., . . Ning, Y. (2019). Group B Streptococcus DNA copy numbers measured by digital PCR correlates with perinatal outcomes. 
Analytical Chemistry, 91(15), 9466-9471.

Lucignano, B., Ranno, S., Liesenfeld, O., Pizzorno, B., Putignani, L., Bernaschi, P., \& Menichella, D. (2011). Multiplex PCR allows rapid and accurate diagnosis of bloodstream infections in newborns and children with suspected sepsis. Journal of Clinical Microbiology, 49(6), 2252-2258.

Molloy, E. J., Wynn, J. L., Bliss, J., Koenig, J. M., Keij, F. M., McGovern, M., . . Mazela, J. (2020). Neonatal sepsis: Need for consensus definition, collaboration and core outcomes. London, UK: Nature Publishing Group.

Mousavi, S. M., Hosseini, S. M., Mashouf, R. Y., \& Arabestani, M. R. (2016). Identification of group B streptococci using 16S rRNA, cfb, scpB, and atr genes in pregnant women by PCR. Acta Medica Iranica, 54(12), 765-770.

NCBI. (n.d.). Gene. Retrieved March 10, 2021, from https://blast.ncbi.nlm.nih.gov/Blast.cgi

NCBI. (n.d.). Gene. Retrieved March 10, 2021, from https://www.ncbi.nlm.nih.gov/

Podbielski, A., Blankenstein, O., \& Lütticken, R. (1994). Molecular characterization of the cfb gene encoding group B streptococcal CAMP-factor. Medical Microbiology and Immunology, 183(5), 239-256.

Primer3. (n.d.). Retrieved March 10, 2021 from https://bioinfo.ut.ee/primer3-0.4.0/

Rao, G. G., \& Khanna, P. (2020). To screen or not to screen women for Group B Streptococcus (Streptococcus agalactiae) to prevent early onset sepsis in newborns: Recent advances in the unresolved debate. Therapeutic Advances in Infectious Disease, 7, Article 2049936120942424.

Schrag, S. J., \& Verani, J. R. (2013). Intrapartum antibiotic prophylaxis for the prevention of perinatal group B streptococcal disease: Experience in the United States and implications for a potential group B streptococcal vaccine. Vaccine, 31, D20-D26.

Schrag, S. J., Farley, M. M., Petit, S., Reingold, A., Weston, E. J., Pondo, T., . . Lynfield, R. (2016). Epidemiology of invasive early-onset neonatal sepsis, 2005 to 2014. Pediatrics, 138(6), Article e20162013.

Schuchat, A. (1998). Epidemiology of group B streptococcal disease in the United States: Shifting paradigms. Clinical Microbiology Reviews, 11(3), 497-513.

Shabayek, S., Abdalla, S., \& Abouzeid, A. M. (2010). Comparison of scpB gene and cfb gene polymerase chain reaction assays with culture on Islam medium to detect Group B Streptococcus in pregnancy. Indian Journal of Medical Microbiology, 28(4), 320-325.

Shah, D. K., Doyle, L. W., Anderson, P. J., Bear, M., Daley, A. J., Hunt, R. W., \& Inder, T. E. (2008). Adverse neurodevelopment in preterm infants with postnatal sepsis or necrotizing enterocolitis is mediated by white matter abnormalities on magnetic resonance imaging at term. The Journal of Pediatrics, 153(2), 170-175.

Shang, S., Chen, G., Wu, Y., Du, L., \& Zhao, Z. (2005). Rapid diagnosis of bacterial sepsis with PCR amplification and microarray hybridization in 16S rRNA gene. Pediatric Research, 58(1), 143-148.

$\begin{array}{lllll}\text { Sigma-Aldrich. } & \text { (n.d.). } & \text { Retrieved } & \text { March } & \text { 10, 2021, }\end{array}$ http://www.oligoarchitect.com/FretSearchServlet 
Stoll, B. J., Hansen, N. I., Adams-Chapman, I., Fanaroff, A. A., Hintz, S. R., Vohr, B., . . . Network, H. D. N. R. (2004). Neurodevelopmental and growth impairment among extremely low-birth-weight infants with neonatal infection. Jama, 292(19), 2357-2365.

Vieira, L. L., Perez, A. V., Machado, M. M., Kayser, M. L., Vettori, D. V., Alegretti, A. P., . . Valério, E. G. (2019). Group B Streptococcus detection in pregnant women: Comparison of qPCR assay, culture, and the Xpert GBS rapid test. BMC Pregnancy and Childbirth, 19(1), 1-8. 